\title{
Hydroxytyrosol rich-mixture from olive mill wastewater and production of green products by feeding Rhodopseudomonas sp. S16-FVPT5 with the residual effluent
}

\author{
Pietro Carlozzi $^{\mathrm{a}, *}$, Maurizia Seggiani $^{\mathrm{c}}$, Antonella Capperucci $^{\mathrm{b}}$, Damiano Tanini $^{\mathrm{b}}$, Patrizia Cinelli ${ }^{\mathrm{c}}$, \\ Andrea Lazzeri ${ }^{\mathrm{c}}$ \\ ${ }^{a}$ Institute of Research on Terrestrial Ecosystems, CNR, Via Madonna del Piano 10, 50019 Sesto Fiorentino (FI), Italy \\ b Department of Chemistry "Ugo Schiff", University of Florence, Via della Lastruccia, 3-13, 50019 Sesto Fiorentino (FI), Italy \\ ${ }^{\mathrm{c}}$ Department of Civil and Industrial Engineering, University of Pisa, Largo Lucio Lazzarino 1, 56122 Pisa, Italy
}

A R T I C L E I N F O

\section{Keywords:}

Hydroxytyrosol-rich mixture

Olive mill wastewater

Rhodopseudomonas sp. S16-FVPT5

poly- $\beta$-hydroxybutyrate

hydrogen

\begin{abstract}
A B S T R A C T
This study disserts on the exploitation of olive mill wastewater (OMW) for the production of both bio-based poly$\beta$-hydroxybutyrate (PHB) and hydrogen $\left(\mathrm{H}_{2}\right)$ by using the residual effluent as feedstock for growing purple bacteria after the recovery of hydroxytyrosol-rich mixtures. In particular, Rhodopseudomonas sp. S16-FVPT5 was fed with either the virgin OMW or dephenolized-OMW (d-OMW). For polyphenols removal, the OMW was treated with activated carbon; subsequently, acidified ethanol $(\mathrm{pH}=3.1)$ at $50{ }^{\circ} \mathrm{C}$ was used as extractor solvent for obtaining hydroxytyrosol-rich mixtures. The maximum hydroxytyrosol content in the resultant polyphenolic mixture was $2.02 \mathrm{~g} / \mathrm{L}$. The highest co-production of PHB (315 mg PHB/L) and $\mathrm{H}_{2}\left(2236 \mathrm{~mL} \mathrm{H}_{2} / \mathrm{L}\right)$ were achieved feeding Rhodopseudomonas sp. S16-FVPT5 with pure d-OMW. The highest hydrogen yield $\left(4.55 \mathrm{~L}\left(\mathrm{H}_{2}\right) / \mathrm{L}_{\mathrm{d}-\mathrm{OMW}}\right)$ was obtained feeding the bacterium with d-OMW, diluted at $25 \%$; by increasing the content of d-OMW into the culture broth the hydrogen yield progressively decreased. Lower results were obtained by feeding the bacterium with a synthetic medium, the cumulative hydrogen was $1855 \mathrm{~mL} \mathrm{H}_{2} / \mathrm{L}$ ); the PHB was $101 \mathrm{mg}$ PHB/L. The highest theoretical light conversion efficiency was $2.36 \%$ with the synthetic medium and $1.99 \%$ when feeding Rhodopseudomonas sp. S16-FVPT5 with d-OMW diluted with water 50\%, v/v.
\end{abstract}

\section{Introduction}

The effluent coming from olive-oil industry is considered one of the most pollutant wastes in the Mediterranean basin due their high content of phenolic compounds. However, these compounds possess beneficial properties for health; for example, they are strong antioxidants and, consequently, the olive oil residues can be represented as an inexpensive source of these natural antioxidants (Ena et al., 2012). The adsorption by activated carbon (AC) is the most frequently used treatment method to remove toxic pollutants such as phenols from aqueous effluents. The recovery of polyphenols from olive mill wastewater (OMW) by AC and organic solvent, such as methanol, have been widely used for the adsorption/desorption processes (Gamel and Kiritsakis, 1999; Cardoso et al., 2005). The OMW, deprived of polyphenols, can represent a suitable feedstock for feeding purple bacteria because it is rich of nutrients; hence, it can be used in industrial biotechnological processes for the combined production of green products.
Nowadays, global energy requirements are mostly dependent on fossil fuels, which eventually lead to foreseeable depletion due to limited fossil energy resources. In addition, the fast climate changes force the researchers to find a solution to overcome the actual fossil-based economy developing a more suitable green economy based on renewable energy sources. In recent times a great deal of attention is being paid to the usage of hydrogen as alternative and eco-friendly fuel throughout the world (Mohan et al., 2007), because from its combustion to generate electricity only water is formed hence it does not contribute to environmental pollution (Miyake, 2014). Biological production of hydrogen $\left(\mathrm{H}_{2}\right)$ from biomass and wastewaters is one of the alternative methods less energy intensive and more environmental friendly where processes can be operated at ambient temperatures and pressures (Mohan et al., 2007; Seifert et al., 2010). The share of the vector hydrogen in the automotive fuel market could grow very fast in the near future, due to both $\mathrm{H}_{2}$ environmental advantage and the use of low-cost feedstock as industrial agro-food residues and/or wastewaters

\footnotetext{
* Corresponding author.

E-mail address: pietromario.carlozzi@cnr.it (P. Carlozzi).
} 
suitable for feeding the photo-fermentative process. Disregarding the artificial photo-assisted hydrogen generation, there are two different light-dependent processes for the $\mathrm{H}_{2}$ production: water biophotolysis, using cyanobacteria and green algae, and photo-fermentation of organic compounds using photosynthetic bacteria (Hallenbeck et al., 2012). Photosynthetic microorganisms could provide a very simple method with relatively minimal investment and resource requirements because the major part of the energy conversion is carried out within the cellule without the need to use complex plants (Miyake, 2014). Since $\mathrm{H}_{2}$ production by nitrogenase $\left(\mathrm{N}_{2}\right.$ ase $)$ is induced by nitrogen deficiency or low nitrogen content in the culture broth, the carbon to nitrogen $(\mathrm{C}: \mathrm{N})$ ratio in the medium is a very important parameter. It has been demonstrated that in the absence of nitrogen all the $\mathrm{e}^{-\mathrm{s}}$ are allocated to $\mathrm{H}_{2}$ production in the $\mathrm{N}_{2}$ ase reaction (Sakurai et al., 2013).

Among the photosynthetic microorganisms, the purple bacteria (PB), a group of Gram-negative pink to purplish-brown bacteria, contain type II reaction center (RC), which cannot use $\mathrm{H}_{2} \mathrm{O}$ as the $\mathrm{e}^{-}$donor in contrast with organisms like cyanobacteria, algae and land plants that contain the photosystem II (PS II). This is because the oxidant generated by the photochemical reaction center (RC) of type II in purple bacteria is not strong enough to extract e from $\mathrm{H}_{2} \mathrm{O}$ (Sakurai et al., 2013). The major groups of bacteria that contain this type of RC are the purple bacteria genera as Rhodobacter, Rhodospirillum, Rhodopseudomonas, etc.; in the purple bacteria, $\mathrm{N}_{2}$ ase activity is induced by nitrogen deficiency. Since nitrogen fixation is a highly energy-demanding process, synthesis of $\mathrm{N}_{2}$ ase is inhibited as long as ammonium is available (Masepohl and Hallenbeck, 2010).

Bioenergy from microorganisms does not compete with food crops, and the photobioreactors for production of green energy can be positioned in marginal areas without competition with agricultural lands (Carlozzi et al., 2010; Carlozzi and Sacchi, 2001).

In conjunction with the production of $\mathrm{H}_{2}$, photosynthetic processes can be explored to produce biopolymers such as polyhydroxyalkanoates (PHAs). PHAs are polyesters synthesized by numerous bacteria that are attracting a great attention due to their thermoplastic properties, similar to that of polypropylene, good mechanical properties and excellent biodegradability in various ecosystems such as fresh water, soil, industrial/domestic compost and seawater. PHAs are among the most promising candidates for the production of biodegradable items for different industrial applications. But, their relatively high cost (7-12 $€ / \mathrm{kg}$ ), compared to other biodegradable polymers such as poly-lactic acid (PLA), has somehow refrained research activity on their use in commodity applications such as packaging and service items, restricting their use to high-value applications, such as those in medical and pharmaceutical sectors. These high market costs are also partly due to the high costs of used carbon sources (e.g. glucose and sucrose) (Bugnicourt et al., 2014).

PHA production using no-cost agro-industrial wastes such as fermented sugar cane molasses, paper mill effluent, cheese whey, palm oil, municipal wastewater, and olive oil mill wastewater is currently attracting considerable attention from researchers, especially for use in mixed microbial culture technologies in order to reduce the actual PHA production costs (Campanari et al., 2017).

In this study, a multi-step process was developed for the valorization of OMW through a first selective recovery of polyphenols (PPs) and the subsequent combined production of $\mathrm{H}_{2}$ and poly- $\beta$-hydroxybutyrate (PHB) by using Rhodopseudomonas sp. S16-FVPT5. The removal of PPs from OMW was carried out by AC. The desorption of the adsorbed PPs was obtained using ethanol; this solvent has several advantages being cheap, recoverable and nontoxic (Mylonaki et al., 2008; Galanakis et al., 2010; Scoma et al., 2012). Multiple adsorption/desorption cycles were performed in order to individuate the optimal operating conditions in terms of adsorption/desorption efficiencies of PPs, chemical oxygen demand (COD) and total volatile fatty acids (TVFAs). The resultant de-phenolized OMW (d-OMW) was used pure or diluted with water as source of nutrients for the combined photo-fermentative production of $\mathrm{H}_{2}$ and PHB using Rhodopseudomonas sp. S16-FVPT5. The performance of the photofermentative process was evaluated varying the dilution of d-OMW in terms of specific cumulative production and yields of $\mathrm{H}_{2}$ and PHB, and light conversion efficiency.

\section{Material and methods}

\subsection{Materials}

The virgin OMW used in the present study came from a three-phase olive oil extraction process in a continuous olive-processing plant located in Tuscany, Italy. The main characteristics of the abovementioned OMW, after centrifugation, were the following: $\mathrm{pH}=3.7$; $\mathrm{COD}=53.2 \mathrm{~g} / \mathrm{L} ; \mathrm{PPs}=5.55 \mathrm{~g} / \mathrm{L}$ and TVFAs $=12.85 \mathrm{~g} / \mathrm{L}$. OMW sample $(200 \mathrm{~L})$ used for the investigation on the recovering of Hydroxytyrosol rich-mixture and co-production of $\mathrm{H}_{2}$ and PHB was stored in an underground reservoir for a period of 80 days. The AC used for the PP removal was supplied by Carboplant S.r.l., Vigevano (PV) - Italy. All properties of the AC have been reported elsewhere (Ena et al., 2012). Acetonitrile, methanol, acetic acid and water (for HPLC), were supplied by Carlo Erba Reagents S.r.l., Cornaredo (Mi) - Italy. Ethanol used for regeneration of AC and desorption of PPs were purchased from Sigma-Aldrich (St. Louis, MO, USA). Hydroxytyrosol was supplied by Phytolab (Vestenbergsgreuth, Germany). Folin-Ciocalteu reagent was purchased from Merck (Darmstadt, Germany).

\subsection{Analytical methods}

Polyphenolic content of the OMW was determined in accordance with the method reported by Folin and Ciocalteu (1927). The total content of PPs was determined at $730 \mathrm{~nm}$ by spectrophotometer (Cary 50, Agilent Technologies Inc., Santa Clara, CA, USA). Determination of hydroxytyrosol in the PPs mixture was carried out by high performance liquid chromatography (HPLC) (ProStar/Dynamax System Liquid Chromatograph, Agilent Technologies Inc., Santa Clara, CA, USA) coupled with a ProStar 335 PDA DAD detector and with the use of a binary gradient elution (Ena et al., 2012). A $4.6 \times 250-\mathrm{mm}$, Sinergy Fusion RP18, $4 \mu \mathrm{m}$ (Phenomenex, Torrance, CA, USA) analytical column was used with the same precolumn $(10 \times 4 \mathrm{~mm})$. All analyses were carried out in triplicate.

Chemical oxygen demand (COD) measurements were performed using a C99 Multiparameter Bench Photometer (HANNA Instruments, Lucca, Italy). Samples ( $2 \mathrm{~mL}$ ) were added to an oxidizing chromatic acid solution and digested for $2 \mathrm{~h}$ at $150{ }^{\circ} \mathrm{C}$ and the measurements were carried out after cooling.

The cell dry weight (CDW) concentration, carbohydrate and protein content of the biomass, elemental analysis of the biomass $(\mathrm{C}, \mathrm{H}, \mathrm{N}, \mathrm{O})$ and the heat of combustion of ash-free biomass $\left(\mathrm{H}_{\mathrm{B}}\right)$ were determined in accordance with Carlozzi and Sacchi (2001). The content of PHB in the biomass was determined in accordance with Padovani et al. (2018). The bacteriochlorophyll (Bchl) was measured according to Carlozzi et al. (2006) and the amount of TVFAs was determined at $530 \mathrm{~nm}$, in accordance with Mato et al. (2005).

The gas mixture $\left(\mathrm{H}_{2}\right.$ plus $\left.\mathrm{CO}_{2}\right)$ from the headspace of the photobioreactor (PBR) was first made to flow into a basin containing a saline $\mathrm{NaOH}$ solution to adsorb $\mathrm{CO}_{2}$; successively $\mathrm{H}_{2}$ was trapped in a calibrated column, where it was collected and the volume measured to determine its production. No $\mathrm{CO}_{2}$ was found inside the calibrated column. This was checked by sampling (in triplicate) $0.1 \mathrm{~mL}$ of the gas from the calibrated column and it was injected into a gas chromatograph (Perkin-Elmer Autosystem) equipped with TCD detector and a Silica Gel 60/80 Grade 12 column (Alltech, Derfield). The calibrated column was refilled with a saline solution of $\mathrm{NaOH}$ every morning. The consumption of acetate was checked with a HPLC (Thermo Finnigan Spectra System 6000 L P). The HPLC was equipped with a C18 analytical column $(250 \times 4.6 \mathrm{~mm})$ and the column temperature was $25^{\circ} \mathrm{C}$. 


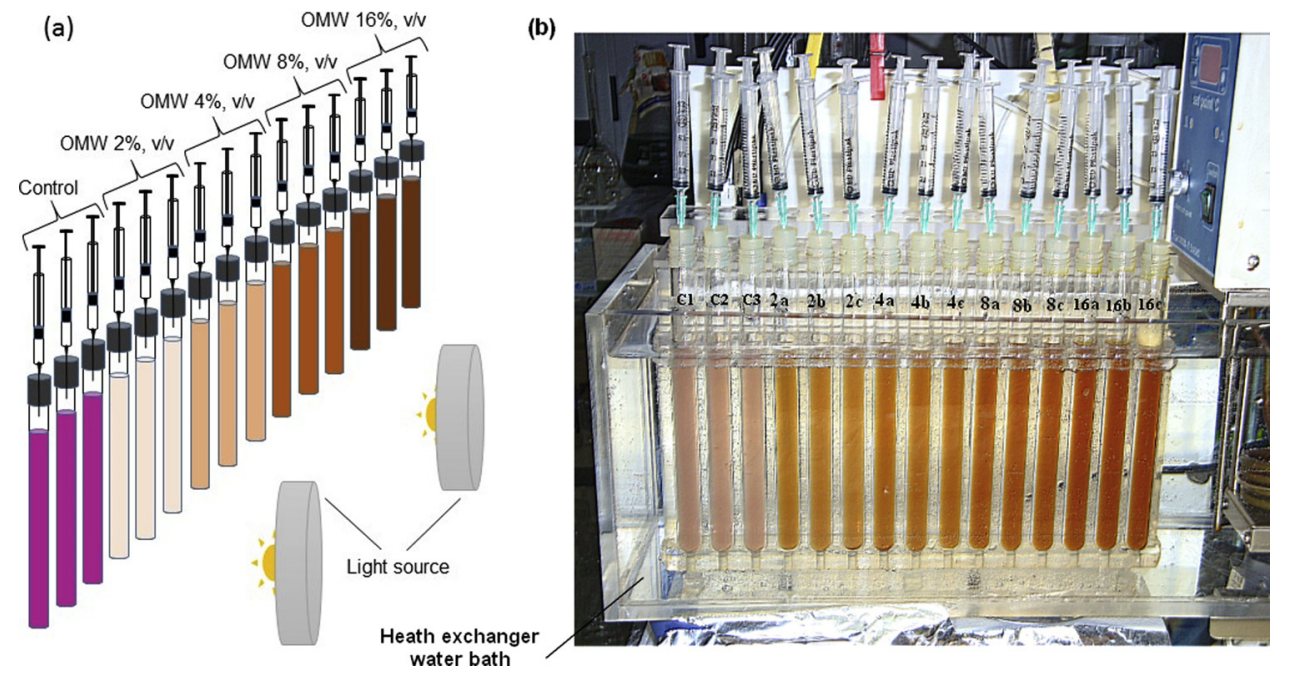

Fig. 1. Cultural system used for testing the growth of Rhodopseudomonas sp. S16-FVPT5 using the culture broths containing untreated OMW diluted with distilled water (2, 4, 8 and 16\%; v/v). Schematic representation of culture system (a); picture of the cultural system (b).

After the removal of the cells by disposable syringe filter units (MFS$13 \mathrm{~mm}, 0.45 \mu \mathrm{m}$ pore size), the supernatant was tested in order to measure the acetate content. The mobile phase consisted of an aqueous 0.1 wt. $\% \mathrm{H}_{3} \mathrm{PO}_{4}$ solution at a flow rate of $1.0 \mathrm{~mL} / \mathrm{min}$ (Carlozzi et al., 2010).

\subsection{Statistical methods}

One-way permutation analyses of variance (PERMANOVA; Anderson et al., 2008) were used to test for differences in terms of production of $\mathrm{H}_{2}$ and biomass among the different concentrations of OMW diluted with water $(2,4,8$ and $16 \%, v / v)$ and the control. Levene's tests were performed to check for homogeneity of dispersion. Four factor levels only, respectively control, 2, 4 and $8 \%$, were investigated for BChl. Unrestricted permutation of raw data, Type I of sum of squares and 9999 permutations were chosen according to Anderson (2001). PERMANOVAs were run on the basis of a Euclidean distance matrix. Pairwise permutational post hoc t-tests were applied when appropriate using a Monte-Carlo p-values. Significance was set at $\mathrm{p}$-value $=0.05$. No $\mathrm{p}$-values correction was applied to permutational tests as suggested by Anderson (2001).

\subsection{Adsorption and desorption process}

The phenolic compounds present in OMW could be counted among those with hydro-soluble characteristics. Among these compounds, there are gallic acid and derivatives, hydroxytyrosol and derivatives, tyrosol and derivatives, syringic acid, coumaric acid and oleuropein. This last is a glucoside that quickly degrades in elenolic acid, hydroxytyrosol and aglycone.

For polyphenols (PPs) removal, the OMW was treated with AC by using the device built by Tecnolab srl, Spello, PG, Italy. Then, PP-rich AC was dried at $38^{\circ} \mathrm{C}$ and divided into several portions and packed into nylon bags for the subsequent desorptions. PPs were extracted using a TIMATIC extractor (Tecnolab srl, Spello, PG, Italy) that permitted to recover PPs using acidified ethanol $(\mathrm{pH}=3.1)$ at $50^{\circ} \mathrm{C}$ as extractor solvent. The time of the extraction varied from 15 to a maximum of $720 \mathrm{~min}$. The process consists of two phases: the first is a dynamic phase comprising a forced filtration; the second is a static phase, during which the adsorbed compounds are transferred from the solid to the liquid phase. In view of the industrial process, either single or double or triple desorption cycles was investigated by using the same extractive solvent.

The efficiency of the adsorption process for PPs, COD and VFAs was evaluated as follows:
$\operatorname{CRE}(\%)=\left(\mathrm{C}_{0}-\mathrm{C}_{\mathrm{f}}\right) / \mathrm{C}_{0} \times 100$

where CRE is the compound removal efficiency, $\mathrm{C}_{0}$ and $\mathrm{C}_{\mathrm{f}}$ indicate the amount of PPs, COD and VFAs, in the OMW, before and after adsorption, respectively.

\subsection{Microorganism and culture conditions}

Rhodopseudomonas sp. S16-FVPT5 coming from the collection of Research Institute on Terrestrial Ecosystems, National Research Council (IRET, CNR) has been used in the present work. The 16S sequences were deposited in GenBank under the following accession numbers: KU899101-KU899105. Rhodopseudomonas sp. S16-FVPT5 was precultured in the synthetic medium (with a composition reported below) at a constant temperature of $30 \pm 0.2{ }^{\circ} \mathrm{C}$ in anaerobic conditions (Sovirel bottles, $100 \mathrm{~mL}$ ) under continuous irradiance of $74 \mathrm{~W} / \mathrm{m}^{2}$ using a 150-W OSRAM power-star HQI-TS lamp. The irradiance was measured using a Quantum/Radiometer/Photometer (model LI-185B, LICOR, Lincoln, Nebraska, USA). The investigation was carried out by feeding the bacterium with virgin OMW and d-OMW. A synthetic medium was used as control, whose composition was $2.0 \mathrm{~g} / \mathrm{L}$ of acetate, $0.5 \mathrm{~g} / \mathrm{L} \mathrm{NH} \mathrm{NH}_{4} \mathrm{Cl} 1.0 \mathrm{~g} / \mathrm{L} \mathrm{KH}_{2} \mathrm{PO}_{4}, 0.4 \mathrm{~g} / \mathrm{L} \mathrm{NaCl}, 0.4 \mathrm{~g} / \mathrm{L} \mathrm{MgSO}_{4} \cdot 7 \mathrm{H}_{2} \mathrm{O}$, $0.05 \mathrm{~g} / \mathrm{L} \mathrm{CaCl} \mathrm{Ca}_{2} \cdot 2 \mathrm{H}_{2} \mathrm{O}, 0.1 \mathrm{mg} / \mathrm{L} p$-aminobenzoic acid and $10 \mathrm{~mL} / \mathrm{L}$ of mineral solution for micronutrients. Mineral solution $(1 \mathrm{~L})$ contained $1.0 \mathrm{mg} \mathrm{CuCl}{ }_{2} \cdot 2 \mathrm{H}_{2} \mathrm{O}, 2.0 \mathrm{mg} \mathrm{NiCl} \cdot 6 \mathrm{H}_{2} \mathrm{O}, 3.0 \mathrm{mg} \mathrm{MnCl}_{2} \cdot 4 \mathrm{H}_{2} \mathrm{O}, 10 \mathrm{mg}$ $\mathrm{ZnSO}_{4} \cdot 7 \mathrm{H}_{2} \mathrm{O}, 20 \mathrm{mg} \mathrm{CoCl}{ }_{2} \cdot 6 \mathrm{H}_{2} \mathrm{O}, 30 \mathrm{mg} \mathrm{H} \mathrm{H}_{3} \mathrm{BO}_{3}, 200 \mathrm{mg} \mathrm{FeSO} \cdot 7 \mathrm{H}_{2} \mathrm{O}$, and $500 \mathrm{mg} \mathrm{Na} 2 \mathrm{MoO}_{4} \cdot 7 \mathrm{H}_{2} \mathrm{O}$. The $\mathrm{pH}$ of the synthetic medium was adjusted to 6.8 by using $\mathrm{HCl} 0.1 \mathrm{mM}$ or $\mathrm{NaOH} 5 \mathrm{wt} . \%$. For the combined production of hydrogen and PHB, the synthetic growth medium was modified, the carbon source (acetate) concentration was increased to the optimal value of $4.0 \mathrm{~g} / \mathrm{L}$ and the nitrogen source $\left(\mathrm{NH}_{4} \mathrm{Cl}\right)$ was replaced with $1.0 \mathrm{~g} / \mathrm{L}$ of Na-glutamate.

The virgin OMW was first centrifuged to remove the solid fraction and then the liquid fraction was diluted with distilled water $(2,4,8$ and $16 \%, \mathrm{v} / \mathrm{v})$; the initial $\mathrm{pH}$ of the culture broth was adjusted at 6.8 and sterilized by autoclaving (temperature $121{ }^{\circ} \mathrm{C}$; pressure 2.0 atm.; time $20 \mathrm{~min}$.). The photofermentative growth experiments with Rhodopseudomonas sp. S16-FVPT5 were carried out in $20 \mathrm{ml}$ (working volume) glass tubes by using the system shown in Fig. $1(\mathrm{a}, \mathrm{b})$, at a constant temperature of $30 \pm 0.2{ }^{\circ} \mathrm{C}$ under continuous irradiance of $74 \mathrm{~W} / \mathrm{m}^{2}$. The amount of inoculation to the photobioreactors (tubes) was $10 \%$ by volume of pre-cultured Rhodopseudomonas sp. S16-FVPT5 in the synthetic medium. Each culture tube was mixed every day with a vortex for $1 \mathrm{~min}$. The experiments were carried out in triplicate. At the 

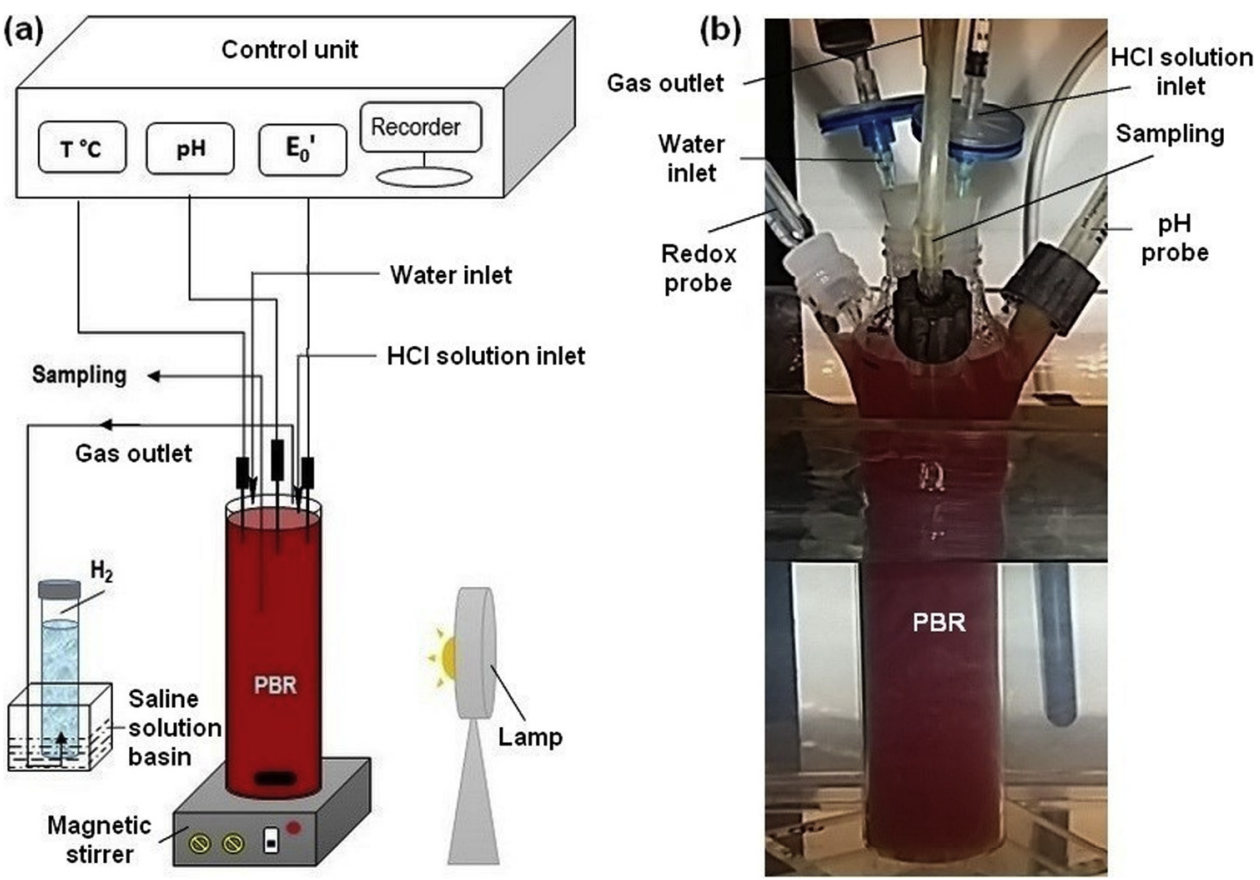

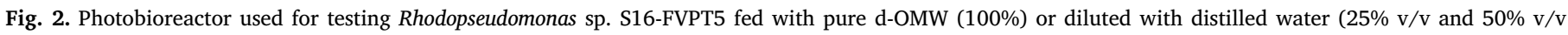
respectively). Schematic representation of the photobioreactor (a); picture of the photobioreactor (b).

end of the experiment, cultures were sampled for analyses.

The d-OMW was used pure $(100 \%)$ or diluted with distilled water $(25 \% \mathrm{v} / \mathrm{v}$ and $50 \% \mathrm{v} / \mathrm{v}$ respectively). A cylindrical-glass photobioreactor with an internal diameter of $4.0 \mathrm{~cm}$ and a working volume of $220 \mathrm{~mL}$ was used (Fig. 2a, b). The initial $\mathrm{pH}$ of the medium was adjusted at 6.8; subsequently, the $\mathrm{pH}$ was adjusted to 7.0 every $24 \mathrm{~h}$. The $\mathrm{pH}$ and the oxidation-reduction potential $\left(\mathrm{E}_{0}{ }^{\prime}\right)$ were monitored continuously. Culture samples were replaced with distilled water.

An appropriate volume of pre-cultured Rhodopseudomonas sp. S16FVPT5 was sampled and cells were collected by means of centrifugation and were washed with physiological solution to remove traces of synthetic salts. The cells were then suspended in the culture broths containing either the synthetic medium or d-OMW (pure o diluted), in order to investigate the medium effect on the PHB accumulation and the hydrogen evolution. The initial BChl and CDW concentrations were $2.0 \mathrm{mg} / \mathrm{L}$ and $0.193 \mathrm{~g} / \mathrm{L}$ respectively. Cultures grown in the photobioreactor shown in Fig. 2(a, b) were mixed continuously by using a magnetic stirrer. The PBR ( $220 \mathrm{~mL}$ working volume) was sterilized through the aforementioned autoclaving process; successively, it was operated under sterile conditions. The growth parameters (temperature, $\mathrm{pH}$ and $\mathrm{E}_{0}$ ') were monitored using probes connected to a control unit (Chemitec srl, Florence, Italy). All experiments were carried out in a thermostatic room of $22{ }^{\circ} \mathrm{C}$, under atmospheric pressure. In order to deaerate the headspace and culture broths, Argon was flowed for $5 \mathrm{~min}$ and subsequently the cultural systems were placed under the abovementioned continuous light conditions.

\subsection{Light conversion efficiency}

The theoretical light conversion efficiency $\left(\mathrm{LCE}_{\mathrm{T}}\right)$ is the key factor in the development of a photosynthetic process aimed at hydrogen production. This factor is calculated on the hypothesis that the substrate is fully converted in $\mathrm{bioH}_{2}$ in accordance as follows:

$\mathrm{LCE}_{\mathrm{T}}=\mathrm{H}_{2, \text { output }} /$ Energy, input $\times 100$

$\mathrm{LCE}_{\mathrm{T}}$ is based on the complete conversion of organic compounds to carbon dioxide and molecular hydrogen (Gest et al., 1962). However, a significant quantitative of biomass is produced together with $\mathrm{bioH}_{2}$, which is due to the bacterial growth (Basak and Das, 2007). Consequently, a real light conversion efficiency $\left(\mathrm{LCE}_{\mathrm{R}}\right)$ has to be introduced and assessed as follows:

$\mathrm{LCE}_{\mathrm{R}}=$ Total Energy, ${ }_{\text {output }} /$ Energy, $_{\text {,input }} \times 100$

where the total energy output is the energy of the $\mathrm{H}_{2}$ and of the biomass produced, while energy input is the irradiance impinged on the reactor surface and the energy of the organic compounds consumed. Details regarding the Eqs. (2) and (3) are reported elsewhere (Carlozzi, 2009).

\section{Results and discussion}

\subsection{OMW as natural feedstock for feeding purple bacteria}

The main characteristics of stored-OMW after centrifugation were the following: $\quad \mathrm{pH}=4.3, \quad \mathrm{COD}=51.5 \mathrm{~g} / \mathrm{L}, \quad \mathrm{PPs}=5.4 \mathrm{~g} / \mathrm{L}$; TVFAs $=19.5 \mathrm{~g} / \mathrm{L}$. The pure effluent is an unsuitable feedstock due to both the high PPs content, which causes an inhibitory effect on the growth of many bacteria, and its black-brownish color (Keskin et al., 2011; Daglia, 2012). Despite the toxic potential of PPs, the possibility of using non-treated diluted OMW was investigated feeding Rhodopseudomonas sp. S16-FVPT5 with different concentrations of OMW diluted with water $(2,4,8$ and $16 \%, v / v)$. The results are shown in Table 1 in terms of production of $\mathrm{H}_{2}$ and biomass after a growth time of $192 \mathrm{~h}$. All PERMANOVAs were significant ( $p$-values $<<0.0001$ ) indicating clear differences in terms of production of $\mathrm{H}_{2}$ and biomass among the different concentrations of OMW diluted with water (2, 4, 8 and $16 \%, \mathrm{v} / \mathrm{v})$ and the control. Results of pairwise permutational post hoc t-tests are shown in the Supplementary File. Broth cultures containing OMW concentration $\geq 2 \%, \mathrm{v} / \mathrm{v}$ had a net inhibitory effect on $\mathrm{H}_{2}$ production, CDW and BChl growth. Conversely, a significant growth stimulation was observed for VFA at OMW concentration $\geq 2 \%$, v/v. A similar observation was reported by Eroğlu et al., 2006 by feeding Rhodobacter sphaeroides O.U.001 with raw OMR diluted with water. Consequently, for the subsequent experiments, OMW was de-phenolized before feeding Rhodopseudomonas sp. S16-FVPT5 that was cultured in the controlled photobioreactor with a working volume of $220 \mathrm{~mL}$. 
Table 1

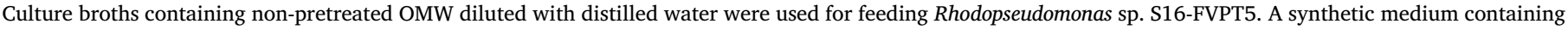
acetate was used as control.

\begin{tabular}{|c|c|c|c|c|c|c|c|c|c|}
\hline \multirow[t]{2}{*}{ Runs } & \multicolumn{2}{|c|}{$\begin{array}{l}\text { CDW } \\
(\mathrm{mg} / \mathrm{L})\end{array}$} & \multicolumn{2}{|c|}{$\begin{array}{l}\text { VFA } \\
(\mathrm{g} / \mathrm{L})\end{array}$} & \multicolumn{2}{|c|}{$\begin{array}{l}\mathrm{PP} \\
(\mathrm{mg} / \mathrm{L})\end{array}$} & \multicolumn{2}{|c|}{$\begin{array}{l}\text { BChl } \\
\text { (mg/L) }\end{array}$} & \multirow[t]{2}{*}{$\begin{array}{l}\text { Cumulative } \mathrm{H}_{2} \\
\left(\mathrm{~mL} \mathrm{H}_{2} / \mathrm{L}\right)\end{array}$} \\
\hline & $\mathrm{t}_{0}$ & $t_{f}$ & $t_{0}$ & $t_{f}$ & $\mathrm{t}_{0}$ & $t_{f}$ & $\mathrm{t}_{0}$ & $t_{f}$ & \\
\hline OMW $2 \%$ & 74 & $57 \pm 06$ & 0.43 & $0.257 \pm 0.021$ & 111 & nd & 0.48 & $0.60 \pm 0.08$ & $139 \pm 28$ \\
\hline OMW 4\% & 74 & $130 \pm 50$ & 0.86 & $0.447 \pm 0.058$ & 222 & nd & 0.48 & $0.87 \pm 0.10$ & $178 \pm 17$ \\
\hline OMW 8\% & 74 & $50 \pm 26$ & 1.72 & $1.280 \pm 0.056$ & 444 & nd & 0.48 & $0.37 \pm 0.05$ & $2.2 \pm 0.5$ \\
\hline OMW 16\% & 74 & $20 \pm 09$ & 3.44 & $3.422 \pm 0.088$ & 888 & nd & 0.48 & nd & 0.0 \\
\hline Control & 74 & $770 \pm 26$ & 2.00 & $0.00 \pm 0.00$ & 0 & nd & 0.48 & $2.74 \pm 0.20$ & $239 \pm 22$ \\
\hline
\end{tabular}

$\mathrm{t}_{0}$, Initial time; $\mathrm{t}_{\mathrm{f}}$, final time; nd, not determined.

\subsection{Removal of PPs and recovery of hydroxytyrosol-rich mixtures}

The main characteristics of OMW after the adsorption process with $100 \mathrm{~g}(\mathrm{AC}) / \mathrm{L}$ were the following: $\mathrm{pH}=5.4, \mathrm{COD}=19.9 \mathrm{~g} / \mathrm{L}, \quad \mathrm{PPs}$ $\leq 0.1 \mathrm{~g} / \mathrm{L}$, TVFAs $=8.4 \mathrm{~g} / \mathrm{L}$ corresponding to average removal efficiency $>98 \%$ for PPs, $61.4 \%$ for COD and $59.6 \%$ for TVFAs. These results demonstrated the high removal efficiency of the used adsorption device, specially, for PP removal from OMW. To desorb PPs and regenerate AC, the acidified ethanol solution was successfully used as extraction solvent showing the feasibility of the adsorption/desorption process investigated. The procedure was optimized in order to fulfill the conditions, which would significantly advantage the feasibility of polyphenols recovery. The temperature at which the operations (desorption) were performed was fixed at $50{ }^{\circ} \mathrm{C}$; lower results were obtained at $30^{\circ} \mathrm{C}$ (data not shown). In order to optimize the extraction time, several tests were carried out increasing the time from 15 to $720 \mathrm{~min}$. Table 2 shows the results concerning the desorption of phenolic compounds carried out with the TIMATIC extractor in terms of amount of hydroxytyrosol desorbed by the AC. As shown, the hydroxytyrosol content into the PP mixture raised increasing the extraction cycles and a maximum hydroxytyrosol content of $2.02 \mathrm{~g} / \mathrm{L}$ was obtained after 3cycles and after $180 \mathrm{~min}$. However, small differences were observed between the extraction times of 120 and 180 , so the time of $120 \mathrm{~min}$ could be taken into consideration as an appropriate period for reaching enough content of hydroxytyrosol. The desorption interval times of 15, 120,180 and 720 min were chosen because they were significantly lower than $24 \mathrm{~h}$, which was a very long time used on previous desorption experiments, carried out by our group (Ena et al., 2012).

The obtained PP mixture is of high interest for both pharmaceutical and cosmetic industries due to the relevant benefits of hydroxytyrosol on human health (Manna et al., 1999; O'Dowd et al., 2004).

\subsection{Combined production of $\mathrm{PHB}$ and $\mathrm{H}_{2}$}

The resultant d-OMW was used as nutritive solution for feeding the photosynthetic process based on Rhodopseudomonas sp. S16-FVPT5. This bacterial strain was grown in the cultural system shown in Fig. 2(a,

Table 2

Hydroxytyrosol content in the polyphenolic mixture obtained by single, double and triple desorption from AC using the same ethanol solvent.

\begin{tabular}{|c|c|c|c|c|c|}
\hline \multicolumn{6}{|c|}{ Hydroxytyrosol amount in the polyphenolic mixture } \\
\hline \multirow{2}{*}{$\begin{array}{l}\text { Number } \\
\text { of } \\
\text { desorptions }\end{array}$} & \multirow[t]{2}{*}{ Unit } & \multicolumn{4}{|c|}{$\begin{array}{l}\text { Desorption time } \\
\text { (min) }\end{array}$} \\
\hline & & 15 & 120 & 180 & 720 \\
\hline Single & $\mathrm{mg} / \mathrm{L}$ & 622 & nd & 733 & 800 \\
\hline Duple & $\mathrm{mg} / \mathrm{L}$ & 1028 & 1370 & 1394 & 1243 \\
\hline Triple & $\mathrm{mg} / \mathrm{L}$ & nd & 1922 & 2018 & 1858 \\
\hline
\end{tabular}

nd; not determined.
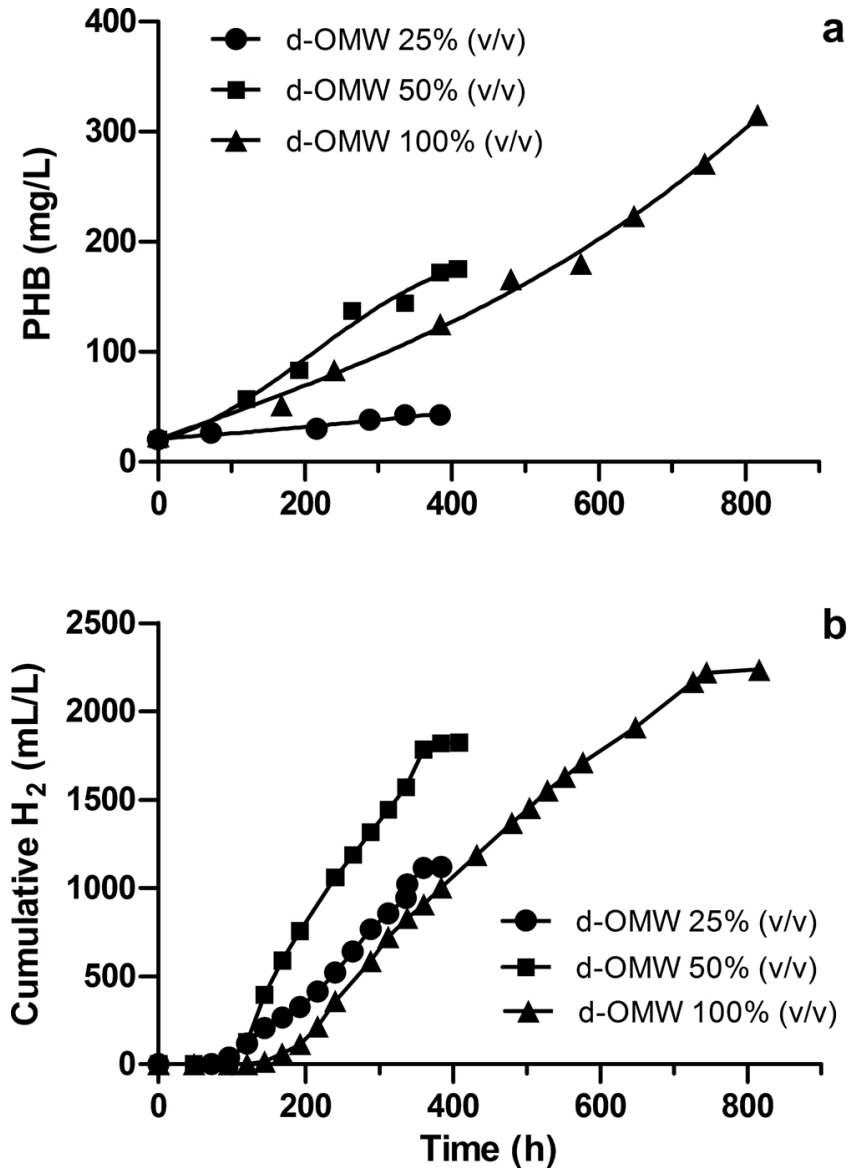

Fig. 3. Combined accumulation of poly- $\beta$-hydroxybutyrate (PHB) (a) and $\mathrm{H}_{2}$ (b) versus time by means of Rhodopseudomonas sp. S16-FVPT5 grown in the culture broths containing pure d-OMW or diluted with water $(50 \%$, v/v or $25 \%$, $\mathrm{v} / \mathrm{v})$.

b) using different culture broths containing pure d-OMW or diluted one with water at $25 \%$ and $50 \%(\mathrm{v} / \mathrm{v})$. Fig. $3(\mathrm{a}, \mathrm{b})$ shows the relative cumulative productions of PHB and $\mathrm{H}_{2}$ by Rhodopseudomonas sp. S16FVPT5, respectively. As shown, after about $400 \mathrm{~h}$ the cumulative PHB and $\mathrm{H}_{2}$ resulted insignificant when the diluted d-OMW at 50\% and 25\% (v/v) were used, reaching PHB concentrations of 175 and $43 \mathrm{mg}$ PHB/L and cumulative $\mathrm{H}_{2}$ productions of 1825 and $1120 \mathrm{~mL} \mathrm{H}_{2} / \mathrm{L}$, respectively. On the other hand, using pure d-OMW, the productions continued over time reaching cumulative PHB and $\mathrm{H}_{2}$ of $315 \mathrm{mg}$ PHB/L and $2236 \mathrm{~mL} \mathrm{H}_{2} / \mathrm{L}$, respectively, after about $800 \mathrm{~h}$. These results are attributable to the fact that the concentrations of the nutritive components increased by increasing the percentage of d-OMW in the culture broth with consequent increase of the metabolic activity of the bacterial biomass as evidenced by higher productions of PHB and $\mathrm{H}_{2}$ obtained 


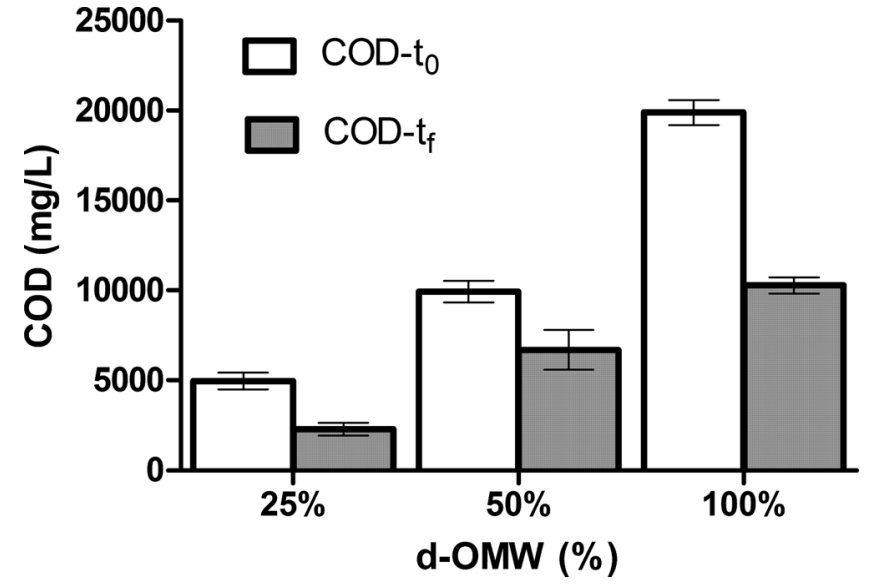

Fig. 4. Chemical oxygen demand (COD) changes in the culture broths containing growing amounts of d-OMW diluted with water $(25 \%$, v/v or $50 \%$, v/v) or pure $(100 \%)$ by means of Rhodopseudomonas sp. S16-FVPT5. COD values were evaluated at the initial time $\left(\mathrm{t}_{0}\right)$ and at the final time $\left(\mathrm{t}_{\mathrm{f}}\right)$.

using 100\% d-OMW. A combined production of $\mathrm{H}_{2}$ and PHB is a major advantage for environmentally friendly technology in utilizing solar energy bioconversion and in turning industrial and sewage wastes into alternative sources of energy and recyclable plastics (Khatipov et al., 1998). In the biorefinery process, the production of biological hydrogen is an important challenge, in light of a $100 \%$ renewability criterion (Deneyer et al., 2016).

In Fig. 4, the initial and final COD values of the different culture broths containing d-OMW are reported. The final time $\left(\mathrm{t}_{\mathrm{f}}\right)$, to which the COD values refer are around $400 \mathrm{~h}$ for 25 and 50 vol.\% d-OMW and $816 \mathrm{~h}$ for $100 \%$ d-OMW. As shown, a significant reduction of the COD values were observed in the culture broths as a result of the combined productions of $\mathrm{PHB}$ and $\mathrm{H}_{2}$. The highest COD removal (54\%) was obtained with the culture broth containing $25 \%$ of d-OMW.

Eroğlu et al. (2011) achieved 30\% of COD removal when Rhodobacter sphaeroides O.U.001 was fed with OMW diluted with water (2\%, $\mathrm{v} / \mathrm{v})$. They increased COD removal to $48 \%$, by adding in the culture broth both $\mathrm{Fe}$ and Mo. Higher COD removal (73\%) was reported by Ghimire et al. (2017) feeding enriched photoheterotrophic culture with dark fermentation effluent of food wastes. The $\mathrm{pH}$ and $\mathrm{E}_{0}$ ' of the cultures were continuously monitored and the results are shown in Fig. 5. The $\mathrm{pH}$ was kept quite stable, over time, by adding $\mathrm{HCl} 0.1 \mathrm{mM}$; it ranged from 6.8 to 7.2 in all cultures tested. On the contrary, regarding the oxidation potential, some important differences emerged during bacterial growth. The $\mathrm{E}_{0}$ ' decreased quickly during the first growth period $(24 \mathrm{~h})$ reaching the value of $-180 \mathrm{mV}$; this behavior was observed in all cultures investigated. In the following period, $\mathrm{E}_{0}{ }^{\prime}$ decreased slowly up to the lowest value $(-512 \mathrm{mV})$. This value stayed stable in the culture with pure d-OMW, but got up to about $-400 \mathrm{mV}$ in Rhodopseudomonas cultures grown in the broths containing diluted d-OMW. A scheme involving redox potential changes of clusters in nitrogenase proteins were reported by Sakurai et al. (2013). Investigating about Feprotein- $\mathrm{ATP}_{2}$ complex and MoFe-protein, the authors showed that the Fe-protein still decreases further up to about $-620 \mathrm{mV}$.

The present study demonstrated that d-OMW could be used pure, without dilution with fresh water, for feeding Rhodopseudomonas in order to produce both bioplastic as PHB and $\mathrm{bioH}_{2}$, so that a dual objective can be reached. This solution avoids the use of clean fresh-water for diluting d-OMW preventing an environmental paradox: "instead of cleaning up the environment, clean fresh water would be contaminated" and satisfy a more general concept "converting waste into resources is better than shredding them".

As comparison, Rhodopseudomonas sp. S16-FVPT5 was also investigated using a synthetic medium, as where acetate and glutamate

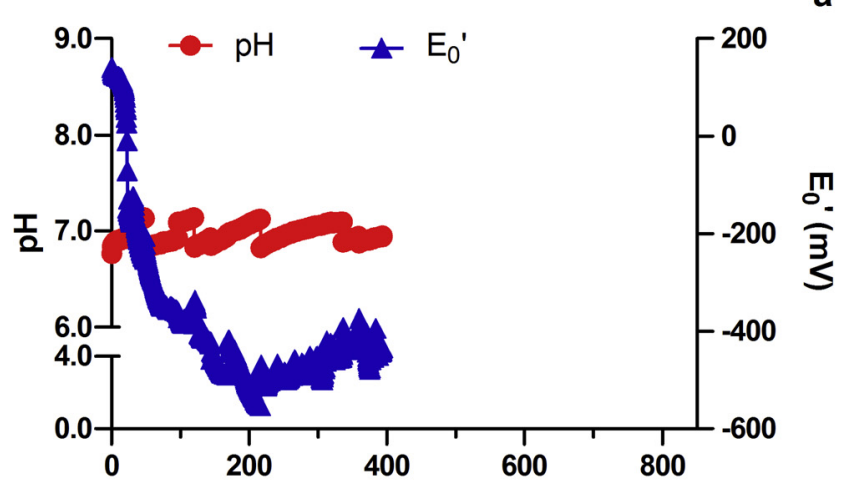

b
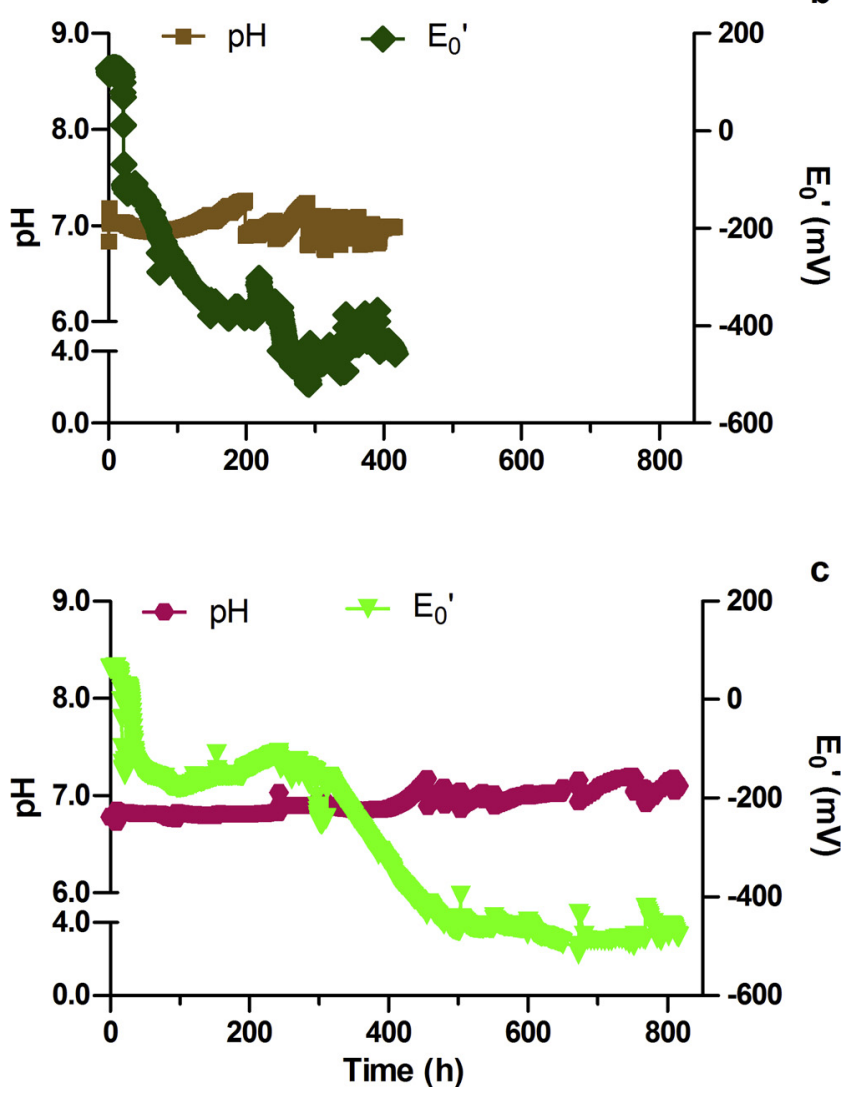

Fig. 5. Changes of $\mathrm{pH}$ and oxidation-reduction potential $\left(\mathrm{E}_{0}{ }^{\prime}\right)$ vs. time when Rhodopseudomonas sp. S16-FVPT5 was fed with three different culture broths containing increasing amounts of d-OMW diluted with distilled water: $25 \%, \mathrm{v} / \mathrm{v}$ (a); 50\%, v/v (b) and 100\%, v/v (c).

were used as carbon and nitrogen sources, respectively. The investigation was carried out operating the photobioreactor in batch mode; results are shown in Fig. 6(a-c). A combined production of PHB and $\mathrm{H}_{2}$ were achieved ( $100 \mathrm{mg} \mathrm{PHB} / \mathrm{L}$ and $1855 \mathrm{~mL} \mathrm{H}_{2} / \mathrm{L}$, respectively) in $336 \mathrm{~h}$ (Fig. 6a). The BChl concentration reached about $11.0 \mathrm{mg} / \mathrm{L}$ at the end of the growth and the initial amount of acetate $(4.0 \mathrm{~g} / \mathrm{L})$ was totally consumed (Fig. 6b). The generation of hydrogen began after $72 \mathrm{~h}$ and continued until acetate was totally consumed. During the hydrogen photoproduction, the $\mathrm{pH}$ was maintained around 7.0 and $\mathrm{E}_{0}{ }^{\prime}$ was about $-550 \mathrm{mV}$ and, only in the last period of growth, it increased to $-475 \mathrm{mV}$ (Fig. 6c). An increase of bacterial biomass was also observed, reaching the concentration of $1.46 \mathrm{~g}(\mathrm{CDW}) / \mathrm{L}$, at $\mathrm{t}=336 \mathrm{~h}$ (data not shown).

The composition of all biomasses achieved growing 

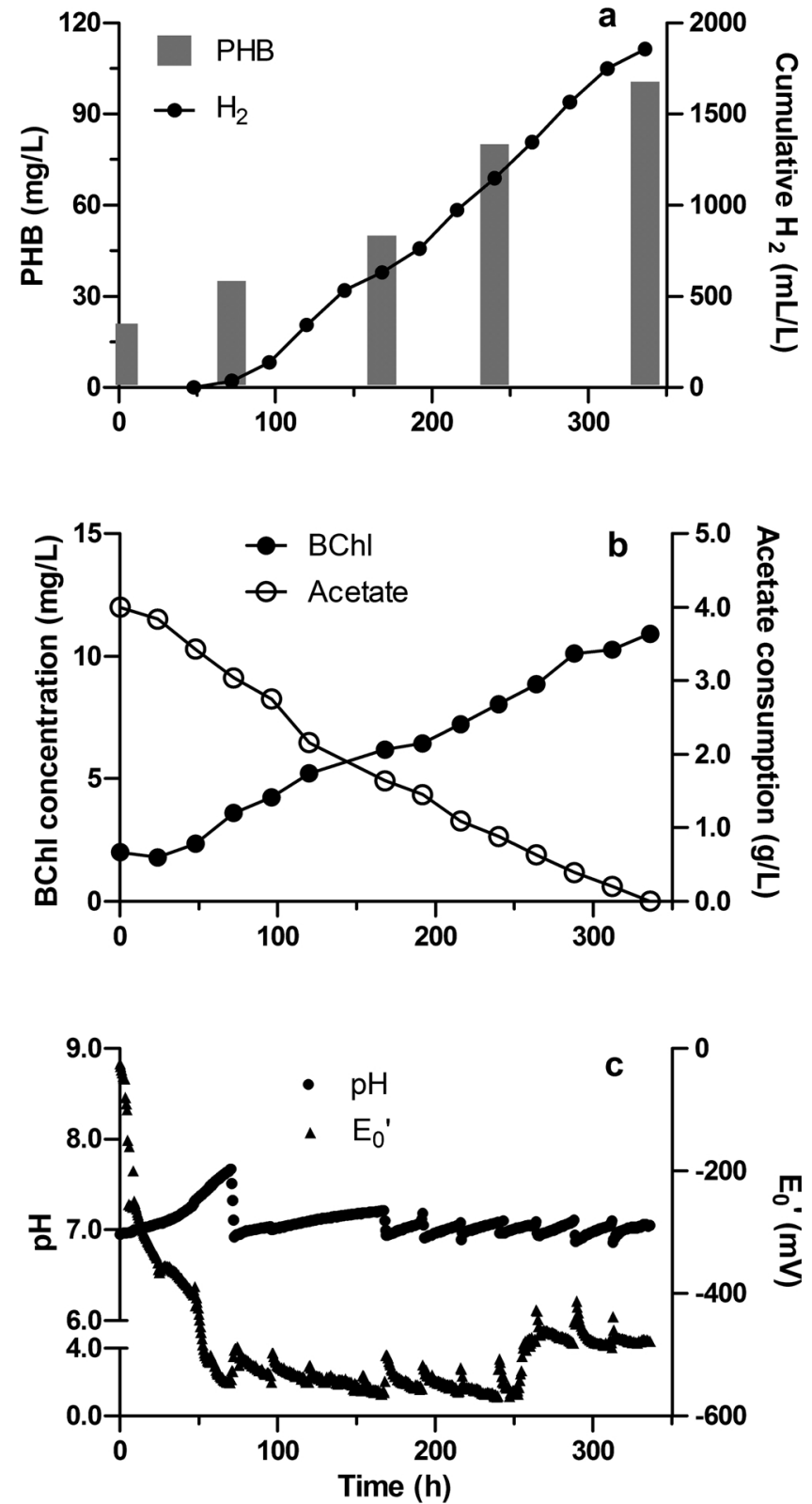

Fig. 6. Rhodopseudomonas sp. S16-FVPT5 grown in the synthetic medium containing acetate and glutamate: combined production of poly- $\beta$-hydroxybutyrate (PHB) and $\mathrm{H}_{2}$ (a); bacteriochlorophyll (BChl) enhancement and acetate consumption vs. time (b); trends of $\mathrm{pH}$ and oxidation-reduction potential $\left(\mathrm{E}_{0}{ }^{\prime}\right)$ vs. time (c).
Rhodopseudomonas sp. S16-FVPT5 with the synthetic medium and with the broths containing different amounts of d-OMW are reported in Table 3. The hydrogen and PHB yields $\left(\mathrm{Y}_{\mathrm{H}}, \mathrm{Y}_{\mathrm{PHB}}\right)$ of Rhodopseudomonas sp. S16-FVPT5 fed with synthetic medium or d-OMW effluents are shown in Table 3. Data are comparable with those reported by Eroğlu et al. (2006), when Rhodobacter sphaeroides O.U.001 was fed with claypretreated OMW diluted with water $(50 \%, \mathrm{v} / \mathrm{v})$.

Table 4 compares the PHB content and cumulative $\mathrm{H}_{2}$ from several studies using different carbon sources as either wastewater or synthetic substrates. The content of PHB in the biomass harvested at the end of the experimental sets raised when increasing the content of d-OMW into culture broths. By culturing Rhodopseudomonas sp. S16-FVPT5 into a culture broth containing pure d-OMW, the dry-biomass collected at the end of the process showed the highest PHB content of $15.7 \%$. This value is very high considering that in this case the PHB is a secondary product during the hydrogen generation. A so high PHB content is comparable with that obtained with Rhodobacter capsulatus fed with dark fermentation effluent of fruit-vegetable wastes, ranging from $11 \%$ to $22 \%$ of dry-biomass (Corona et al., 2017). Higher PHB content (32.5\% of CDW) have been recently reported by Ghimire et al. (2017) when growing an adapted culture of Rhodobacter sphaeroides AV1b. Lower PHB content (6.3\% of CDW) was reported by the same researcher team feeding mixed photofermentative cultures with diluted dark fermentation effluents achieving a concomitant production of $169 \mathrm{~mL} \mathrm{H}_{2}$ / L of culture.

A comparison of the specific production activities of PHB and $\mathrm{H}_{2}$ using volatile fatty acids was reported by Cardeña et al. (2017); $\mathrm{H}_{2}$ and PHB formations compete for the reducing equivalents released from bacteria growing under certain substrates, showing that the formation of $\mathrm{H}_{2}$ or PHB is detrimental to the formation of each other. The accumulation of PHB in the biomass is undesired for hydrogen photoproduction reducing its yield.

OMW valorization towards PHAs production could be relevant because the procedure did not require any pretreatment of OMW (Campanari et al., 2017). The process investigated in the present study exalts the recovery of the hydroxytyrosol-rich mixture that is a bioactive and profitable product.

\subsection{Light conversion efficiency}

Several researchers have used the light conversion efficiency as parameter for evaluating the efficiency of photofermentative processes (Carlozzi and Sacchi, 2001; Akkerman et al., 2002; Boran et al., 2012). Sakurai et al. (2013) calculated maximum solar energy conversion efficiencies varying from $11 \%$ to $25.6 \%$. A much lower value $(7.6 \%)$ was reported by Carlozzi and Sacchi (2001), when Rhodopseudomons palustris 42OL was cultured, outdoors, using an underwater tubular photobioreactor and taking into account, for the purple bacteria, a photosynthetic available radiation from 400 to $900 \mathrm{~nm}$ (64\% of the spectrum of solar radiation). Our results regarding the light conversion efficiency are shown in Table 3 . The highest $\mathrm{LCE}_{\mathrm{T}}$ was obtained by using the

Table 3

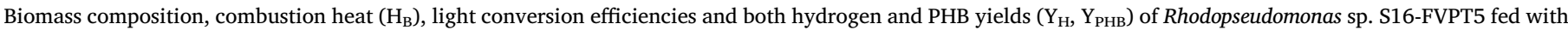
synthetic medium or d-OMW effluents.

\begin{tabular}{|c|c|c|c|c|c|c|c|c|}
\hline \multirow{2}{*}{$\begin{array}{l}\text { Culture } \\
\text { broths }\end{array}$} & \multirow{2}{*}{$\begin{array}{l}\text { Growth } \\
\text { mode }\end{array}$} & \multicolumn{2}{|c|}{ Biomass composition } & \multirow{2}{*}{$\begin{array}{l}\mathrm{H}_{\mathrm{B}} \\
\text { (kcal/g) }\end{array}$} & \multirow{2}{*}{$\begin{array}{l}\mathrm{LCE}_{\mathrm{T}} \\
(\%)\end{array}$} & \multirow{2}{*}{$\begin{array}{l}\mathrm{LCE}_{\mathrm{R}} \\
(\%)\end{array}$} & \multirow{2}{*}{$\begin{array}{l}\mathrm{Y}_{\mathrm{H}} \\
\mathrm{L} \mathrm{H}_{2} / \mathrm{L}_{\mathrm{d}-\mathrm{OMW}}\end{array}$} & \multirow{2}{*}{$\begin{array}{l}\mathrm{Y}_{\mathrm{PHB}} \\
\mathrm{mg} \mathrm{PHB} / \mathrm{L}_{\mathrm{d}-\mathrm{OMW}}\end{array}$} \\
\hline & & $\begin{array}{l}\text { Protein } \\
(\%)\end{array}$ & $\begin{array}{l}\text { Carbohydrate } \\
(\%)\end{array}$ & & & & & \\
\hline Synthetic & Batch & 46.52 & 19.83 & 6.2116 & 2.36 & 5.03 & - & - \\
\hline $\begin{array}{l}\text { d-OMW } \\
\text { Diluted (25\%) }\end{array}$ & Batch & 45.44 & 20.94 & 6.1043 & 1.31 & 2.13 & 4.55 & 89.6 \\
\hline $\begin{array}{l}\text { d-OMW } \\
\quad \text { Diluted (50\%) }\end{array}$ & Batch & 37.99 & 10.03 & 6.6330 & 1.99 & 4.85 & 3.65 & 350.0 \\
\hline $\begin{array}{l}\text { d-OMW } \\
\text { Pure }(100 \%)\end{array}$ & Batch & 39.65 & 11.27 & 6.5601 & 1.18 & 2.83 & 2.24 & 315.0 \\
\hline
\end{tabular}


Table 4

Comparison of PHB content and cumulative $\mathrm{H}_{2}$ from several studies carried out with different PB strains using different carbon sources.

\begin{tabular}{|c|c|c|c|c|c|c|c|}
\hline Purple bacterial strain & Carbon source & Nitrogen source & $\begin{array}{l}\text { PHB concentration } \\
(\mathrm{mg} \mathrm{PHB} / \mathrm{L})\end{array}$ & $\begin{array}{l}\text { PHB } \\
(\% \mathrm{CDW})\end{array}$ & $\begin{array}{l}\text { Cumulative } \mathrm{H}_{2} \\
\left(\mathrm{~mL} \mathrm{H} \mathrm{H}_{2} / \mathrm{L}\right)\end{array}$ & $\begin{array}{l}\text { Culture time } \\
\text { (h) }\end{array}$ & References \\
\hline \multirow[t]{4}{*}{ Rhodopseudomonas sp. S16-FVPT5 } & d-OMW (100\%) & - & 315 & 15.7 & 2236 & 816 & \multirow[t]{4}{*}{ This study } \\
\hline & d-OMW diluted (50\%) & - & 175 & 11.9 & 1825 & 408 & \\
\hline & d-OMW diluted (25\%) & - & 42 & 3.2 & 1118 & 384 & \\
\hline & Acetate & Glutamate & 101 & 7.5 & 1855 & 336 & \\
\hline \multirow{2}{*}{$\begin{array}{l}\text { Rhodobacter sphaeroides } \\
\quad \text { O.U. } 001\end{array}$} & Lactate & Glutamate & 200 & 19.8 & - & 96 & \multirow[t]{2}{*}{ Yiğit et al. (1999) } \\
\hline & $30 \%$ sugar refinery & Glutamate & 500 & 70.4 & 35 & 96 & \\
\hline $\begin{array}{l}\text { Rhodobacter sphaeroides } \\
\quad \text { O.U.001 }\end{array}$ & $\begin{array}{l}\text { OMW diluted with water }(2 \%, \mathrm{v} / \\
\text { v) }\end{array}$ & - & $39^{*}$ & - & $250^{*}$ & 124 & Eroğlu et al. (2010) \\
\hline \multirow{4}{*}{$\begin{array}{l}\text { Rhodobacter sphaeroides AV1b } \\
\text { Mixed photofermentative } \\
\text { culture }\end{array}$} & VFAs (Lactate, propionate, & Ammonium & 1865 & 32.5 & 914 & 960 & \multirow{4}{*}{$\begin{array}{l}\text { Ghimire et al. } \\
\text { (2017) }\end{array}$} \\
\hline & butyrate, acetate) & Ammonium & - & (Max & 169 & $(792)$ & \\
\hline & Dark fermentation effluent & & & $39.2)$ & & - & \\
\hline & (DFE) & & & 6.3 & & & \\
\hline \multirow[t]{6}{*}{ Rhodobacter sphaeroides RV } & Acetate & Ammonium & - & $\sim 39.0$ & - & 13 & \multirow{6}{*}{$\begin{array}{l}\text { Khatipov et al. } \\
\text { (1998) }\end{array}$} \\
\hline & Acetate & N-deficiency & - & $\sim 37.0$ & - & 26 & \\
\hline & Acetate & Glutamate & - & $\sim 27.0$ & - & 26 & \\
\hline & Lactate & $\mathrm{N}$-deficiency & - & $\sim 28.0$ & yes & 22 & \\
\hline & Lactate & Glutamate & - & $\sim 7.0$ & yes & 24 & \\
\hline & Glucose & Ammonium & - & $\sim 8.0$ & - & 13 & \\
\hline \multirow{5}{*}{$\begin{array}{l}\text { Rhodobacter capsulatus } \\
\text { ATCC } 17015 \\
\text { Enric. photoheterotrophic } \\
\text { culture (IZT) } \\
\text { Rhodobacter capsulatus } \\
\text { ATCC } 17015\end{array}$} & Dark fermentation effluent & \multirow[t]{5}{*}{-} & - & $22.0^{\mathrm{a}}$ & $866^{\mathrm{a}}$ & $720^{\mathrm{a}}$ & \multirow{5}{*}{$\begin{array}{l}\text { Corona et al. } \\
(2017)\end{array}$} \\
\hline & \multirow[t]{4}{*}{ (DFE) } & & - & $11.0^{\mathrm{a}}$ & $1340^{\mathrm{a}}$ & $720^{\mathrm{a}}$ & \\
\hline & & & - & $30.8^{\mathrm{b}}$ & $590^{\mathrm{b}}$ & $720^{\mathrm{b}}$ & \\
\hline & & & & & & & \\
\hline & & & & & & & \\
\hline Rhodopseudomonas sp. S16-VOGS3 & Glycerol plus glucose & - & 424 & 18.0 & - & 700 & $\begin{array}{l}\text { Padovani et al. } \\
\text { (2018) }\end{array}$ \\
\hline
\end{tabular}

* mg PHB/Lomw.

a Continue illumination.

b Light/dark cycle 30/30 min.

synthetic medium (5.03\%); a very similar value $(4.85 \%)$ was also obtained when using d-OMW diluted with water $(50 \%, \mathrm{v} / \mathrm{v}) . \mathrm{LCE}_{\mathrm{T}}$ values were about 2.3 times lower than $\mathrm{LCE}_{\mathrm{R}}$. Hence, $\mathrm{LCE}_{\mathrm{R}}$ resulted more adequate than $\mathrm{LCE}_{\mathrm{T}}$ for overcoming the gap of the theoretical photodissimilation of organic carbon-sources into $\mathrm{H}_{2}$ and $\mathrm{CO}_{2}$ against the real photo-conversion into $\mathrm{H}_{2}$ plus $\mathrm{CO}_{2}$ plus PHB-rich biomass (Ghimire et al., 2017).

Feeding Rhodopseudomonas sp. S16-FVPT5 with d-OMW, a PHB-rich biomass was significantly co-produced together with $\mathrm{H}_{2}$. An inverse relationship was observed regarding the hydrogen yield $\left(\mathrm{Y}_{\mathrm{H}}\right)$ and $\mathrm{d}$ OMW content in the culture broth: "The lower the d-OMW amount in the culture broth, the higher the $\mathrm{Y}_{\mathrm{H}}$ ". On the contrary, the PHB yield $\left(\mathrm{Y}_{\mathrm{PHB}}\right)$ grew when the d-OMW was used pure or diluted with water $(50 \%, \mathrm{v} / \mathrm{v})$. In this last case, the highest $\mathrm{Y}_{\mathrm{PHB}}\left(350 \mathrm{mg} \mathrm{PHB} / \mathrm{L}_{\mathrm{d}-\mathrm{OMW}}\right)$ was obtained. On the other hand, it is known that the PHB accumulation represents an alternative pathway for discharging excess reducing power and a reserve material such as PHB increases under unbalanced growth conditions (Melnicki et al., 2009).

\section{Conclusions}

This study demonstrated the efficient use of the OMW in the recovery of valuable polyphenolic mixtures with high concentration of hydroxytyrosol $(>2.0 \mathrm{~g} / \mathrm{L})$. The resultant polyphenol-free OMW was used as suitable feedstock for Rhodopseudomonas sp. S16-FVPT5 used to co-produce $\mathrm{PHB}$ and $\mathrm{H}_{2}$, which represents both attractive alternatives to common petrol plastics (not biodegradable) and fossil fuels, respectively. The highest $\mathrm{Y}_{\mathrm{H}}$ of $4.55 \mathrm{~L}\left(\mathrm{H}_{2}\right) / \mathrm{L}_{\mathrm{d}-\mathrm{OMw}}$ was obtained when using the culture broth containing d-OMW, diluted at $25 \%$, while the higher PHB yield of $350 \mathrm{mg} \mathrm{PHB} / \mathrm{L}_{\mathrm{d}-\mathrm{O} w}$ was achieved when feeding the photobioreactor with culture broth containing 50 vol.\% of d-OMW. Nonetheless, the highest content of PHB (15.7\%) in dry-biomass was achieved with pure d-OMW. The results, obtained on small scale, showed that the production of PHB by purple bacteria, using d-OMW as feedstock, is feasible. Combining the recovery of hydroxytyrosol rich- mixture with the wastewater treatment and the production of valuable products ( $\mathrm{PHB}$ and $\mathrm{H}_{2}$ ) could render the process very attractive and economically feasible.

\section{Declaration of interests}

The authors declare that they have no known competing financial interests or personal relationships that could have appeared to influence the work reported in this paper.

\section{Acknowledgements}

The present work was financed by the Ente Cassa di Risparmio di Firenze, Italy (Practice n. 2014.0986). This research was also supported by Tuscan Region with the Project "PHA" - POR FESR 2014-2020 (Bando 2-RSI 2014)) grant number 3389.30072014.068000241 and the Project "PROSEV", Fondo Europeo Agricolo per lo Sviluppo Rurale (FEASR), Asse Leader Piano di Sviluppo Rurale 2007 to 2013, Tuscan Region - Misura 124-Bando. The authors wish to thank Dr. Alessandro Bergo, Dr. Cristina Pintucci and Dr. Giulia Padovani for having carried out some analyses on polyphenol mixture and biomasses and Dr. Giovanni Emiliani for phylogenetic analysis of PB strain.

"This paper is dedicated to the memory of our colleague and friend Professor Alessandro Degl'Innocenti".

\section{Appendix A. Supplementary data}

Supplementary material related to this article can be found, in the online version, at doi:https://doi.org/10.1016/j.jbiotec.2019.02.006.

\section{References}

Akkerman, I., Janssen, M., Rocha, J., Wijffels, R.H., 2002. Photobiological hydrogen production: photochemical efficiency and bioreactor design. Int. J. Hydrogen Energy 27, 1195-1208. https://doi.org/10.1016/S0360-3199(02)00071-X.

Anderson, M.J., 2001. A new method for non-parametric multivariate analysis of 
variance. Aust. Ecol. 26, 32-46. https://doi.org/10.1046/j.1442-9993.2001.01070.x. Anderson, M.J., Gorley, R.N., Clarke, K.R., 2008. PERMANOVA + For Primer: Guide to Software and Statistical Methods, first ed. PRIMER-E Ltd, Plymouth.

Basak, N., Das, D., 2007. The prospect of purple non-sulfur (PNS) photosynthetic bacteria for hydrogen production: the present state of the art. World J. Microb. Biotechnol. 23, 31-42. https://doi.org/10.1007/s11274-006-9190-9.

Boran, E., Özgür, E., Yücel, M., Gündüz, U., Eroglu, I., 2012. Biohydrogen production by Rhodobacter capsulatus in solar tubular photobioreactor on thick juice dark fermenter effluent. J. Clean. Prod. 31, 150-157. https://doi.org/10.1016/j.jclepro.2012.03. 020 .

Bugnicourt, E., Cinelli, P., Lazzeri, A., Alvarez, V., 2014. Polyhydroxyalkanoate (PHA): review of synthesis, characteristics, processing and potential applications in packaging. Express Polym. Lett. 8 (11), 791-808. https://doi.org/10.3144/ expresspolymlett.2014.82.

Campanari, S., Augelletti, F., Rossetti, S., Sciubba, F., Villano, M., Majone, M., 2017. Enhancing a multi-stage process for olive oil mill wastewater valorization towards polyhydroxyalkanoates and biogas production. Chem. Eng. J. 317, 280-289. https:// doi.org/10.1016/j.cej.2017.02.094.

Cardeña, R., Valdez-Vazquez, I., Buitrón, G., 2017. Effect of volatile fatty acids mixtures on the simultaneous photofermentative production of hydrogen and polyhydroxybutyrate. Bioproc. Biosyst. Eng. 40, 231-239. https://doi.org/10.1007/ s00449-016-1691-9.

Cardoso, S.M., Guyot, S., Marnet, N., Lopes-da-Silva, J.A., Renard, C.M.G.C., Coimbra, M.A., 2005. Characterisation of phenolic extracts from olive pulp and olive pomace by electrospray mass spectrometry. J. Sci. Food Agric. 85, 21-32. https://doi.org/10. $1002 /$ jsfa.1925.

Carlozzi, P., 2009. The effect of irradiance growing on hydrogen photoevolution and on kinetic growth in Rhodopseudomonas palustris, strain 42OL. Int. J. Hydrogen Energy 34 (19), 7949-7958. https://doi.org/10.1016/j.ijhydene.2009.07.083.

Carlozzi, P., Sacchi, A., 2001. Biomass production and studies on Rhodopseudomonas palustris grown in an outdoor, temperature controlled, underwater tubular photobioreactor. J. Biotechnol. 88, 239-249. https://doi.org/10.1016/S0168-1656(01) 00280-2.

Carlozzi, P., Pushparaj, B., Degl'Innocenti, A., Capperucci, A., 2006. Growth characteristics of Rhodopseudomonas palustris cultured outdoors, in an underwater tubular photobioreactor, and investigation on photosynthetic efficiency. Appl. Microbiol. Biotechnol. 73, 789-795. https://doi.org/10.1007/s00253-006-0550-z.

Carlozzi, P., Buccioni, A., Minieri, S., Pushparaj, B., Piccardi, R., Ena, A., Pintucci, C., 2010. Production of bio-fuels (hydrogen and lipids) through a photofermentation process. Bioresour. Technol. 101 (9), 3115-3120. https://doi.org/10.1016/j. biortech.2009.12.049.

Corona, V.M., Le Borgne, S., Revah, S., Morales, M., 2017. Effect of light-dark cycles on hydrogen and poly-b-hydroxybutyrate production by a photoheterotrophic culture and Rhodobacter capsulatus using a dark fermentation effluent as substrate. Bioresour. Technol. 226, 238-246. https://doi.org/10.1016/j.biortech.2016.12.021.

Daglia, M., 2012. Polyphenols as antimicrobial agents. Curr. Opin. Biotechnol. 23, 174-181. https://doi.org/10.1016/j.copbio.2011.08.007.

Deneyer, A., Ennaert, T., Cavents, G., Dijkmans, J., Vanneste, J., Courtin, C.M., Dusselier, M., Sels, B.F., 2016. Compositional and structural feedstock requirements of a liquid phase cellulose-tonaphtha process in a carbon- and hydrogenneutral biorefinery context. Green Chem. 18, 5594-5606. https://doi.org/10.1039/c6gc01644h.

Ena, A., Pintucci, C., Carlozzi, P., 2012. The recovery of polyphenols from olive mill waste using two adsorbing vegetable matrices. J. Biotechnol. 157 (4), 573-577. https://doi. org/10.1016/j.jbiotec.2011.06.027.

Eroğlu, E., Eroğlu, I., Gündüz, U., Turker, L., Yücel, M., 2006. Biological hydrogen production from olive mill wastewater with two-stage processes. Int. J. Hydrogen Energy 31, 1527-1535. https://doi.org/10.1016/j.ijhydene.2006.06.020.

Eroğlu, E., Gündüz, U., Yücel, M., Eroğlu, I., 2010. Photosynthetic bacterial growth and productivity under continuous illumination or diurnal cycles with olive mill wastewater as feedstock. Int. J. Hydrogen Energy 35, 5293-5300. https://doi.org/10. 1016/j.ijhydene.2010.03.063.

Eroğlu, E., Gündüz, U., Yücel, M., Eroğlu, I., 2011. Effect of iron and molybdenum addition on photofermentative hydrogen production from olive mill wastewater. Int. J. Hydrogen Energy 36, 5895-5903. https://doi.org/10.1016/j.ijhydene.2011.02.062.

Folin, O., Ciocalteu, V., 1927. On tyrosine and tryptophane determination in proteins. J. Biol. Chem. 27, 627-650.

Galanakis, C.M., Tornberg, E., Gekas, V., 2010. Recovery and preservation of phenols from olive waste in ethanolic extracts. J. Chem.Technol. Biotechnol. 85 (8), 1148-1155. https://doi.org/10.1002/jctb.2413.

Gamel, T.H., Kiritsakis, A., 1999. Effect of methanol extracts of rosemary and olive vegetable water on the stability of olive oil and sunflower oil. Grasas Aceites 50 (5), 345-350.

Gest, H., Ormerod, J.G., Ormerod, K.S., 1962. Photometabolism of Rhodospirillum rubrum: light-dependent dissimilation of organic compounds to carbon dioxide and molecular hydrogen by an anaerobic citric acid cycle. Arch. Biochem. Biophys. 97, 21-33. https://doi.org/10.1016/0003-9861(62)90039-5.

Ghimire, A., Valentino, S., Frunzo, L., Pirozzi, F., Lens, P.N.L., Esposito, G., 2017. Concomitant biohydrogen and poly- $\beta$-hydroxybutyrate production from dark fermentation effluents by adapted Rhodobacter sphaeroides and mixed photofermentative cultures. Bioresour. Technol. 217, 157-164. https://doi.org/10.1016/j.biortech. 2016.03.017.

Hallenbeck, P.C., Abo-Hashesh, M., Ghosh, D., 2012. Strategies for improving biological hydrogen production. Bioresour. Technol. 110, 1-9. https://doi.org/10.1016/j. biortech.2012.01.103.

Keskin, T., Abo-Hashesh, M., Hallenbeck, P.C., 2011. Photofermentative hydrogen production from wastes. Bioresour. Technol. 102, 8557-8568. https://doi.org/10.1016/ j.biortech.2011.04.004.

Khatipov, E., Miyake, M., Miyake, J., Asada, Y., 1998. Accumulation of poly- $\beta$-hydroxybutyrate by Rhodobacter sphaeroides on various carbon and nitrogen substrates. FEMS Microbiol. Lett. 162, 39-45. https://doi.org/10.1016/S0378-1097(98) 00099-8.

Manna, C., Galletti, P., Cucciolla, V., Montedoro, G., Zappia, V., 1999. Olive oil hydroxytyrosol protects human erythrocytes against oxidative damages. J. Nutr. Biochem. 10 (3), 159-165. https://doi.org/10.1016/S0955-2863(98)00085-0.

Masepohl, B., Hallenbeck, P.C., 2010. Nitrogen and molybdenum control of nitrogen fixation in the phototrophic bacterium Rhodobacter capsulatus. In: In: Hallenbeck, P.C. (Ed.), Recent Advances in Phototrophic Prokaryotes, Advances in Experimental Medicine and Biology 675. Springer Science+ Business Media, LLC, pp. 49-70. https://doi.org/10.1007/978-1-4419-1528-3_4.

Mato, I., Suárez-Luque, S., Huidobro, J.F., 2005. A review of the analytical methods to determine organic acids in grape juices and wines. Food Res. Int. 38, 1175-1188. https://doi.org/10.1016/j.foodres.2005.04.007.

Melnicki, M.R., Eroglu, E., Melis, A., 2009. Changes in hydrogen production and polymer accumulation upon sulfurdeprivation in purple photosynthetic bacteria. Int. J. Hydrogen Energy 34, 6157-6170. https://doi.org/10.1016/j.ijhydene.2009.05.115.

Miyake, L., 2014. Hydrogen production using photosynthetic bacteria. In: Anazawa, H., Shimizu, S. (Eds.), Microbial Production: From Genome Design 263 to Cell Engineerin. Springer, Osaka, Japan, pp. 263-281. https://doi.org/10.1007/978-4 431-54607-8_23.

Mohan, S.V., Babu, V.L., Sarma, P.N., 2007. Anaerobic biohydrogen production from dairy wastewater treatment in sequencing batch reactor (AnSBR): effect of organic loading rate. Enzyme Microbial. Technol. 41, 506-515. https://doi.org/10.1016/j. enzmictec.2007.04.007.

Mylonaki, S., Kiassos, E., Makris, D.P., Kefalas, P., 2008. Optimisation of the extraction of olive (Olea europaea) leaf phenolics using water/ethanol-based solvent systems and response surface methodology. Anal. Bioanal. Chem. 392, 977-985. https://doi.org/ 10.1007/s00216-008-2353-9.

O’Dowd, Y., Driss, F., Dang, P.M.C., Elbim, C., Gourgerot-Pocidalo, M.A., Pasquier, C., ElBenna, J., 2004. Antioxidant effect of $\mathrm{OH}$-tyrosol a polyphenol from olive oil: scavenging of hydrogen peroxide but not superoxide anion produced by human neutrophilis. Biochem. Pharmacol. 68 (10), 2003-2008. https://doi.org/10.1016/j. bcp.2004.06.023.

Padovani, G., Emiliani, G., Giovanelli, A., Traversi, M.L., 2018. Assessment of glycerol usage by five different purple non-sulfur bacterial strains for bioplastic production. J. Environ. Chem. Eng. 6, 616-622. https://doi.org/10.1016/j.jece.2017.12.050.

Sakurai, H., Masukawa, H., Kitashima, M., Inoue, K., 2013. Photobiological hydrogen production: bioenergetics and challenges for its practical application. J. Photochem. Photobiol. Chem. 17, 1-25. https://doi.org/10.1016/j.jphotochemrev.2013.05.001.

Scoma, A., Pintucci, C., Bertin, L., Carlozzi, P., Fava, F., 2012. Increasing the large scale feasibility of a solid phase extraction procedure for the recovery of natural antioxidants from olive mill wastewaters. Chem. Eng. J. 198-199, 103-109. https://doi. org /10.1016/j.cej.2012.05.079.

Seifert, K., Waligorska, M., Laniecki, M., 2010. Hydrogen generation in photobiological process from dairy wastewater. Int. J. Hydrogen Energy 35, 9624-9629. https://doi. org/10.1016/j.ijhydene.2010.07.015.

Yiğit, D.O., Gündüz, U., Türker, L., Yücel, M., Eroğlu, I., 1999. Identification of by-products in hydrogen producing bacteria; Rhodobacter sphaeroides O.U. 001 grown in the waste water of a sugar refinery. J. Biotechnol. 70, 125-131. https://doi.org/10. 1016/S0168-1656(99)00066-8. 